\title{
Hotel California
}

\author{
Nine Antico
}

Sapristi, 2016

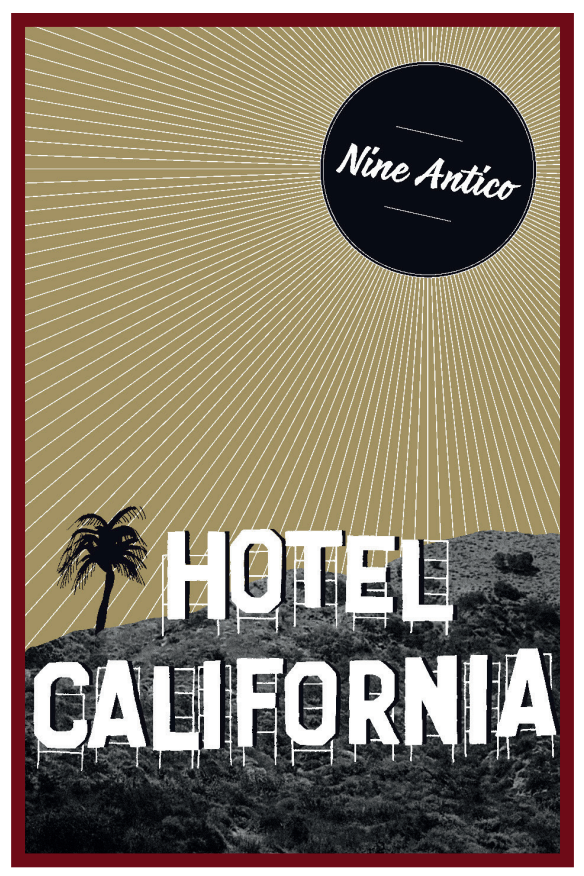

$\mathrm{P}$

AREce ser que el filósofo Arthur Schopenhauer (1788-1860), fervoroso melómano, dijo que «en la música todos los sentimientos vuelven a su estado puro y el mundo no es sino música hecha realidad». Sea cierta o no la autoría de la frase, me gusta la cita, su significado. Entender la música como algo más que una suave $-\mathrm{O}$ abrupta- conjunción de notas y timbres y configurarla como una fuerza motriz de la realidad humana es parte de nuestra propia trascendencia, como especie dominante en este plantea en tanto que somos criaturas inteligentes. Y por tanto, emocionales.

Nine Antico debutó en el cómic con un fanzine de expresivo nombre, Rock this way, y ha colaborado en revistas de títulos tan inequívocos como Minimum Rock'n'Roll o Discobabel. En su trayectoria, en fin, lo musical viene de serie, adherido a un ADN creativo. Su carrera como autora de novelas gráficas se inicia con Le Goût du Paradis (Ego Comme X, 2008), logra notoriedad con Coney Island Baby (L'Association, 2010, recuerdos desde el título a Lou Reed) y Girls Don't Cry (Glénat, 2010, otro guiño musical, a The Cure), y ha proseguido con Tonight (Glénat, 2012) y I love Alice (Les Requins Marteaux, 2012), para cerrar su carrera de momento con la novela gráfica que nos ocupa. El primero y Girls don't cry han gozado de traducción al castellano (Ponent Mon y EDT, respectivamente). Sirva este ortodoxo repaso bibliográfico de Nine Antico para reclamar más: más Antico en la lengua de Quevedo. De momento podemos disfrutar de Hotel California, su obra más reciente.

Volvemos al guiño rockero en un título (The Eagles en este caso) para un cómic que es netamente musical. Un acercamiento al mundo lateral pero capaz de mover montañas de las groupies, esas chicas dispuestas a todo para poder contar a sus nietos que le han practicado una gayola a Jim Morrison. Hace unos años la banda brasileña Cansei de Ser Sexy — por cierto, mayoritariamente formada por mujeres - cantaban «Music is my hot sex», un buen título alternativo para un cómic que finalmente trata de música, pasión, y mujeres en tránsito - adolescentes, en fin-. Porque la música, sobre todo la música rock, es evidentemente un asunto cálido, sexual. Hay algo efectivamente sex y hot, que a los locos por el rock siempre nos ha gustado, en la música del diablo. Hotel California es una historia de márgenes difusos 


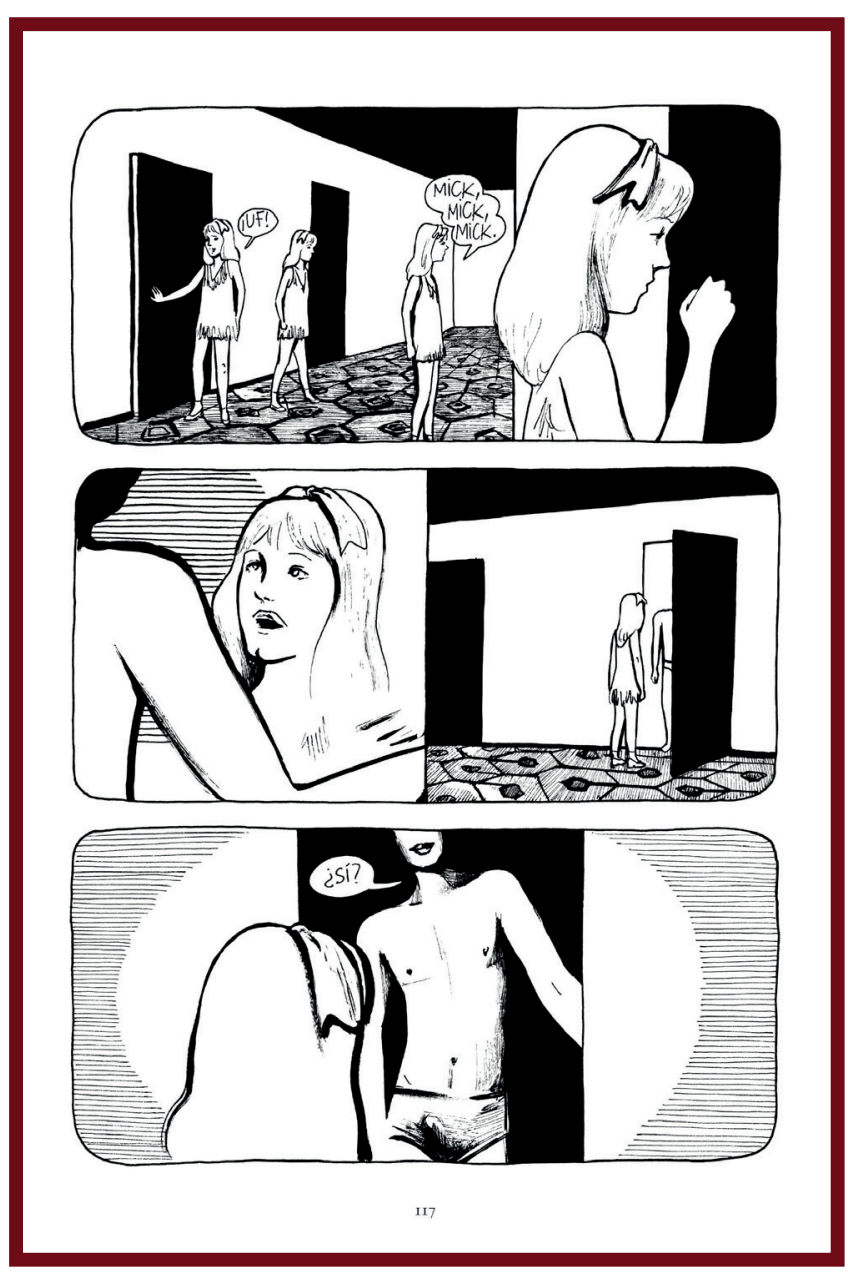

y narrativa poco concreta, como un fluido de secuencias y anécdotas (nada anecdóticas, por otro lado, cuando los coprotagonistas son Jim Morrison, Phil Spector o John Lennon) que unifican la identidad personal y hasta feminista de una joven enamorada de la música, con las cualidades del rock como apuesta por una forma de vida. Curiosamente «Ricitos», la protagonista de la novela gráfica, mantiene un férreo control de los límites éticos que no quiere franquear $-\mathrm{y}$ de los que desea quebrantar, también-. Quiere que respeten su virginidad pero no le importa dar y recibir otros placeres de las estrellas del rock, ejemplo sutil del «nosotras decidimos» aplicado a la vida en general y a la libertad sexual en particular.

El apodo de la chica es interesante: «Ricitos» es una mujer rubia de cabe1lo lacio, pero una de las primeras escenas del cómic nos revela que cuando la lluvia lo moja, se le riza, lo cual hace que sus colegas empiecen a llamarla así. El agua, como la música, la transforma. Si yo tuviera que asociar el rock a un estado de la materia sería el líquido. Un líquido que empapa la realidad, que nos rodea con calidez e imprime carácter a nuestras vidas. Otra escena importante sucede en el segundo capítulo en una playa. Surf, y olas nocturnas. En ese capítulo, tras bañarse de noche, le preguntan si no le da miedo hacerlo así, temerariamente a oscuras, a lo que «Ricitos» responde «Un poco, pero no me alejo mucho, me quedo en la orilla». «No se sabe lo que hay en el fondo», es la respuesta sensata. Entonces la chica pregunta: «DDe qué?». Metáfora de la propia protagonista de Hotel California: una mujer que se zambulle no solo en mares nocturnos, sino también en el mundo líquido del rock, los excesos, la adoración mitómana y la posibilidad de solidificar todo ello a través de la carne y el deseo. En ambas apuestas hay algo de aventura, o al menos de descontrol. Hay un pacto entre un cantante y una groupie, sellado con sexo. En la comunicación ambas partes saldrán fortalecidas y sin duda ese anhelo mutuo forma parte del todo que es el rock and roll way of life.

Ese modo de vida queda relatado perfectamente en el libro, pero Antico va más allá. Lo que nos está mostrando es un retrato de la mujer en los años cincuenta y sobre todo sesenta del pasado siglo. Parte de la era Elvis Presley para instalar a una joven «en el lugar indicado 
en el momento adecuado", como relata la propia Antico en la contraportada del tomo. Un momento de profundos cambios sociales, donde el papel de la mujer en el mundo (y más el de la mujer joven) se recompone a ritmo de pop, comunas californianas que expanden por el mundo ideologías liberales y la ubicación de conceptos como el amor y el deseo en un nuevo plano, ajeno a corsés pacatos. Es el escenario en el que muchas mujeres, muy jóvenes en muchos casos, decidieron cambiar los patrones sociales e identitarios que las sociedades occidentales tenían reservados a ellas. En parte lo lograron gracias a esa capacidad de bucear los fondos oscuros, desconocidos, de las aguas de la música rock, compartiendo líquidos y humores con sus estrellas, a las que ellas con sus actos conscientes y liberados fortalecían en ese papel rutilante, $\mathrm{y}$ al tiempo se fortalecían a sí mismas como mujeres proactivas y sexuales. Los sesenta fue un tiempo en que la igualdad de sexos era, aún, una meta lejana, y la cultura hippie y rock posiblemente de las primeras que comenzó a romper esas barreras. Con inocencia, quizá de un modo desenfocado e irreal (porque al final acostarte con el cantante-estrella varón puede no ser el camino más lógico para la igualdad) pero, en su momento, vital para una nueva cultura.

Este doble discurso, feminista universal y sobre el tránsito a la madurez particular, lo articula Antico en un cómic donde la planificación es exquisita. No solo en las elipsis narrativas o en la composición de los capítulos, sino también en la delicada diagramación de la página. Una que responde a un programa global: toda la novela gráfica se articula en páginas dominadas por tres filas de vértices suavemente redondeados - como en lo líquido, en este cómic no abundan las aristas-, en cuyo interior juega la autora con divisiones de viñetas. Esto se rompe ocasionalmente en páginas-viñeta, generalmente a modo de cierre de capítulo o bien para resaltar una escena concreta, que congela así en un momento y espacio determinados, como esa aparición fugaz de John Lennon que remata el capítulo dedicado... a los Stones. Este esquema más o menos inflexible se demuestra fluido y natural, estético pero nunca tramposo, a lo cual ayuda además un prólogo que va por libre, con planificaciones más caprichosas o esteticistas y sobre todo con un par de páginas notables: las que presentan las actuaciones de Elvis «the pelvis» en «The Milton Berle Show» y en el «Steve Allen show». Las famosas actuaciones del obsceno y coital cimbreo son dibujadas por Antico en un grupo de viñetas que describen una cruz en la página. El prólogo revela como «Ricitos» estaba ahí, delante del televisor. Al final del

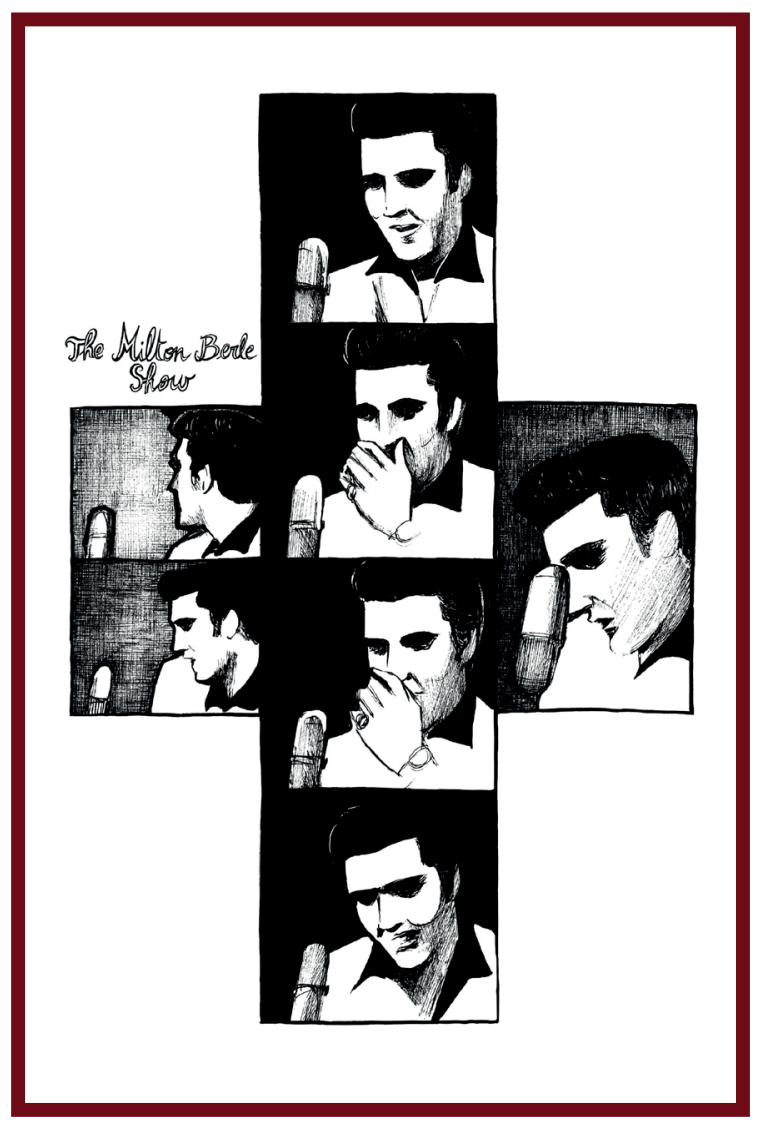


prólogo la niña / mujer se retira a su cuarto, y fantasea recostada, ante dos pósteres, uno del propio Elvis, otro de un Sagrado Corazón de Jesús. Nine Antico propone una identificación del cantante con una pulsión elevada, y describe sin acentos la personalidad bondadosa y pura de su protagonista. Pureza, que no mojigatería, como el grueso de esta novela gráfica nos va a revelar.

Todo es eficaz y notable en Hotel California: hay escenas oníricas —vuelo en alfombra mágica incluido - contadas con pulso prosaico, y momentos cotidianos que no se desprenden del halo del sueño — como, sin ir más lejos, la escena de la playa arriba señalada—, hay un Pepito Grillo con forma de muñeca Barbie, y riqueza de detalles nada ociosos como el remarcado pijote que luce Mick Jagger en su entrepierna, un sexo nada disimulado dentro del pantalón. Y hay diálogos concisos in media res, y silencios maravillosos con miradas explícitas. Lo que es capaz de narrar el dibujo de Antico sin apoyos textuales, en este sentido, nos dice mucho de su calidad como ilustradora. Ese dibujo exquisito, con un aire a boceto circunstancial pero que resulta exacto y ajustado, es tan poético y sensual como algunos delirios de la escuela francesa de las vanguardias sesenteras: hay ecos de Moebius y sobre todo de Guy Peellaert y del italiano Guido Crepax. También por otro lado la mirada sensitiva y naive de Marjane Satrapi o la selva naturalista de Powerpaola se sienten cercanas, y... ¿Pero qué estoy haciendo? ¿He comenzado hablando de estados puros, de liquidez y del pene de Mick Jagger y vamos a acabar recitando influencias de vademécum?

Sería una insensatez.

\section{Octavio Beares}

Octavio Beares comenzó a hacerse oír en la red con un nick, tan tonto como otros muchos, pero por el que aún guarda cariño. A los pocos años decide olvidarse de ese Señor Punch y frrma con su nombre real. Asi, se le ha podido leer en sus dos identidades por diversos proyectos, autogestionados o de terceros. Su blog personal (en activo desde 2005) es El Octavio Pasajero, su blog sobre tebeos, Serie de Viñetas. Mantiene otro más sobre The Sandman al que promete dar continuidad, algún día de estos. Y además se ha prodigado por medios varios, de la revista online Viñeta en Palabras a la web cultural Culturamas, pasando por Rockdelux o el diario Faro de Vigo, donde bace una sección más o menos periódica sobre historieta desde 2009. Ha comisariado un par de exposiciones sobre historieta. Le gusta la música alternativa y el post hardcore, aunque sabe que ya no tiene edad. 